University of Nebraska - Lincoln

DigitalCommons@University of Nebraska - Lincoln

Publications from USDA-ARS / UNL Faculty

U.S. Department of Agriculture: Agricultural

Research Service, Lincoln, Nebraska

2008

\title{
The Role of Databases in Areawide Pest Management
}

\author{
Vasile Catana \\ Oklahoma State University \\ Norman Elliott \\ United States Department of Agriculture-Agricultural Research Service, norman.elliott@ars.usda.gov \\ Kris Giles \\ Oklahoma State University \\ Mustafa Mirik \\ Texas A\&M University \\ David Porter \\ United States Department of Agriculture-Agricultural Research Service
}

See next page for additional authors

Follow this and additional works at: https://digitalcommons.unl.edu/usdaarsfacpub

Part of the Agricultural Science Commons

Catana, Vasile; Elliott, Norman; Giles, Kris; Mirik, Mustafa; Porter, David; Hein, Gary L.; Peairs, Frank; and Michels, Jerry, "The Role of Databases in Areawide Pest Management" (2008). Publications from USDAARS / UNL Faculty. 650.

https://digitalcommons.unl.edu/usdaarsfacpub/650

This Article is brought to you for free and open access by the U.S. Department of Agriculture: Agricultural Research Service, Lincoln, Nebraska at DigitalCommons@University of Nebraska - Lincoln. It has been accepted for inclusion in Publications from USDA-ARS / UNL Faculty by an authorized administrator of DigitalCommons@University of Nebraska - Lincoln. 


\section{Authors}

Vasile Catana, Norman Elliott, Kris Giles, Mustafa Mirik, David Porter, Gary L. Hein, Frank Peairs, and Jerry Michels 


\title{
The Role of Databases in Areawide Pest Management
}

\author{
Vasile Catana, ${ }^{1}$ Norman Elliott ${ }^{2}$ Kris Giles, ${ }^{1}$ \\ Mustafa MIRIK, ${ }^{3}$ DAVId PORTER, ${ }^{2}$ GARY HEIN, ${ }^{4}$ \\ FRANK PEAIRS ${ }^{5}$ AND JERRY MICHELS ${ }^{3}$ \\ 1Oklahoma State University, Department of Entomology and Plant \\ Pathology, Stillwater, Oklahoma, USA \\ 2US Department of Agriculture, Agricultural Research Service, \\ Plant Science Research Laboratory, Stillwater, Oklahoma, USA \\ ${ }^{3}$ Texas A\&M University, Agricultural Experiment Station, Bushland, \\ Texas, USA \\ ${ }^{4}$ Department of Entomology, University of Nebraska Panhandle R\&E \\ Center, Scottsbluff, Nebraska, USA \\ ${ }^{5}$ Department of Bioagricultural Sciences and Pest Management, Colorado \\ State University, Fort Collins, Colorado, USA
}

\section{Introduction}

The simplest definition of the term 'database' is given in Webster's dictionary as 'a comprehensive collection of related data organized for convenient access, generally in a computer' (Random House, 1996). This term appeared in the late 1960s because of the evolution of computer software and the need to distinguish the specialized computer systems for the storage and manipulation of data, called database management systems (DBMS) (Neufeld and Cornog, 1986). Today, the acronym 'DBMS' is universally understood within Information Technology (IT), just like the acronym ' $B t$ ' for 'Bacillus thuringiensis' is in the field of biological pest control. At the present time there are numerous DBMS products available on the market. The most popular are Oracle $^{\odot}, \mathrm{dBase}^{\odot}, \mathrm{DB} 2^{\odot}$, MS SQL Server ${ }^{\odot}$ and Access ${ }^{\odot}$. Access is a part of the Microsoft Office product and can be considered as a prototype of DBMS with limited functionality. These products vary in price and capacity, and therefore the budgetary constraints and the requirements of a particular database application determine their utility.

The evolution of database products has been rapid, reflecting advances in the theory of databases during the last 35-40 years. Beginning with simple data files with direct access, these database products now include very sophisticated file systems with complex interrelationships. More recently, there has been a series of new database applications named Relational Database Management Systems (RDBMS). 
Their development was a product of the advancement in IT, which forced DBMS to adapt. One of these advancements was the creation of distributed computer systems using local or wide-area networks (LAN/WAN) at the end of the 1980s and early 1990s (Date, 2003). These networks stimulated development of new methods for remote database connection, and the improvements of client/server technologies when databases are organized on a computer server separated from those remotely accessed and used to enter data. The uses of DBMS can be very diverse, but this chapter focuses on the application of DBMS in the field of biology, more specifically in entomology and integrated pest management (IPM).

The first uses of databases in biology were mainly to share knowledge about a particular subject. An elegant example of this type of application is deciphering the genetic code of a particular organism. This type of application has been typically addressed by collaboration of research teams working at different geographic locations (King, 2004). For example, scientists communicating or collaborating through a database application announced in April 2003 that the human genome (DNA sequence) was completely decoded (Human Genome Project, 2003). The potential uses of DBMS in plant protection are diverse, and the benefits of using DBMS are not limited to information dissemination as suggested in some publications (e.g. Xia et al., 2002). In fact, DBMS can be used to address many problems in biology, from research questions like deciphering the genetic code to building and maintaining national biodiversity inventories.

\section{Database and IPM}

Today, the acronym IPM is universally accepted to mean integrated pest management. Although there are many definitions of IPM, most stress the role of information and a systems approach to decision making in pest management (Kogan, 1998). In principle, IPM is an ecologically sound strategy that relies on natural mortality factors such as natural enemies, weather, crop management and pesticides when needed to control pests (Kogan, 1998). Thus, many IPM programmes seek to integrate non-chemical control tactics as much as possible for pest management. The US Department of Agriculture and the Environmental Protection Agency work to decrease pesticide application by demonstrating a variety of alternative control techniques to producers in order to minimize pesticide use. These techniques include biological control, genetic resistance, tillage, crop rotation and a wide variety of cultural control methods and other techniques (Dent, 1995).

Two often-ignored components of IPM implementation are database organization and data analysis for purposes of facilitating management decisions. The definition of IPM implies that managing pests is a complex process including many internal and external factors. The chosen strategy is, ideally, based on detailed knowledge of the current state of the agricultural system, future behaviour of the system and the options available for pest control. Appropriately integrating all of this information for a complex agricultural system is often beyond the capability of IPM practitioners. Clearly, control decisions in many IPM systems are data intensive, requiring the use of DBMS and decision-making tools, such as expert systems. 
There are many examples of database implementation in IPM, a few of which are discussed in this chapter. At the beginning of the $1980 \mathrm{~s}$ in the Netherlands, a disease and pest management system was implemented for winter wheat based on information collected in producer fields (Zadoks, 1981). The system was so efficient that other European countries developed their own version of the Dutch project (e.g. Germany and Norway). Folkedal and Breving (2004) give a detailed description of the wheat database implemented in Norway. In the middle of the $1980 \mathrm{~s}$ in Byelorussia (ex-USSR), a mainframe-oriented database for Colorado potato beetle (Leptinotarsa decemlineata Say) was developed to optimize insecticide use in large areas.

During the 1960s in the UK, a network of 16 suction traps (Rothamsted Insect Survey) was activated mainly for aphid monitoring (Tatchell, 1991; Knight et al., 1992). The data collected by the Rothamsted Insect Survey were used to describe fundamental factors affecting the dynamics of aphid populations and to provide information on aphid control for growers and other pest managers. Presently, there is a series of similar suction trap networks throughout Western and Central Europe. In 1999, various European countries decided to organize the EXAMINE project (EXploitation of Aphid Monitoring systems IN Europe). The information provided by the EXAMINE network has been very useful in helping to define the role of aphids, not only as pests but also as vectors of plant disease (EXAMINE, 2000).

Over the last 20-25 years, computer applications have focused mainly on simulation models and decision-support systems for pest management, and did not make progress toward extensive use of databases. For example, Legg and Bennett (1992, 1993) developed a computer-based decision support system to aid managers with Russian wheat aphid control in the western Great Plains of the USA, and implemented the system on hand-held computers used in the field. The system has components for selecting an appropriate economic injury level or threshold for automated decision making through a sequential sampling scheme, and for providing management support in cases where sampling continues to a user-defined maximum number without having reached a control decision. In another example, Mann et al. (1986) developed an advisory system for cereal aphid management. The system was essentially based on simulation models for aphid population dynamics.

Later systems developed along similar lines but included the creation of a database as a constituent part of the computer-based advisory system (Zintzaras and Tsitsipis, 2003; Elliott et al., 2004). Perini and Susi (2004) developed a 'systemic' approach to build decision-support systems (DSS) used in agriculture by the advisory service for pest management in Italy. Murali et al. (1999) described the impact of a DSS product - 'PC - Plant Protection' on agriculture in Denmark after it had been commercialized in 1993. This system is distributed by the Danish Agricultural Advisory Centre and has been well accepted by growers because of increased profits flowing from the reliable and economically valid recommendations provided by the system.

As a rule, insect pests have very large geographic distributions; therefore both research and management may be more efficient when accomplished by multiple teams located throughout the dispersal range of the pest (Taylor, 1977; Elliott et al., 1998). Implementation of a database can be very powerful if several teams simultaneously work on a common project at geographically separated locations. Areawide pest management (AWPM) programmes typically are of this type (Faust and 
Chandler, 1998), often with both state and federal research teams working in a coordinated fashion on specific demonstration sites at several geographic locations. After the establishment of the project goals, the entomologists and specialists in other relevant disciplines typically formulate tasks to standardize a common data collection protocol and to implement it at all locations. The protocol can set the standards for management practices, and can include the same sampling and monitoring methods for a project. When all the participants in an AWPM project follow the same protocol, with the evaluation of the data performed on a project-wide basis, the programmes are particularly amenable to, and in need of a database where information can be entered, analysed and summarized project wide.

\section{Other IT Tools for Plant Protection}

A common database in AWPM projects guarantees that compatible and concise data are collected from different geographic locations. One obvious, straightforward and useful addition to data collected at several geographic locations is to include the longitude and latitude using a Global Position System (GPS) receiver (Nemenyi et al., 2003). Today, there are relatively inexpensive hardware and software products that can combine GPS with computers (Ohio Geospatial Program, 2003). These products determine the coordinates of the sample location with high accuracy and are very easy to use in field conditions. Moreover, the use of these tools can reduce the work involved in database development because of the electronically collected data from the field.

When the coordinates of the sample locations are built into the structure of an AWPM database, a bridge can be developed between the collected information and software that facilitates spatial data analysis. For example, Geographic Information Systems (GISs) can be used to visualize and preliminarily analyse the spatially referenced data. Zintzaras and Tsitsipis (2003) describe this type of application. Their information system includes aphid data from suction and yellow traps. It also has a Windows-based application that creates contour maps representing the spatial expansion of particular aphid species.

We argue that, in AWPM projects, a project-wide database should be considered as a starting point so that monitoring and management activities can be undertaken on a project-wide basis without excessive data recoding and compilation of data. Data recoding and compilation create inherent problems (errors and compatibility) when research teams operate independently and maintain separate databases, even if attempts are made to standardize data collection for all sites. With a database, data from all sites are entered into the database in a consistent format and are accessible for all participants to permit comparative analysis simultaneously. At the outset of such a project, it is important to develop and implement consistent sampling and monitoring methods to be used by all teams involved in the project. The use of hand-held computers for entering data in the field is helpful in this respect, because data entry templates can be constructed using software packages such as Farmworks Sitemate ${ }^{\odot}$ at the beginning of the project. The templates ensure that all individuals who collect and enter data use the same format. As the data accumulate over time, 
the value of the database increases substantially for addressing questions of both a planned and unanticipated nature. This has been an important issue proved by projects such as EXAMINE, because continuously collected data over time and space have been invaluable for addressing research questions such as detecting and predicting the impact of changes in land use on the dynamics of aphids considered as key pests in many terrestrial agroecosystems (EXAMINE, 2000).

Today the majority, if not all, DBMSs permit application through web-based development. In this context, the work of Sivertsen (2005) is relevant. Sivertsen (2005) developed a database to combine an agrometeorological system with simulation models for making measurements and prognoses of crop development over time and for monitoring and predicting crop diseases and other pests. A web site containing real-time information on pest problems, densities and density fluctuations over time could be a valuable resource to alert growers and other pest managers of the pest status or need for pest monitoring in their area. The potential application of this approach is illustrated in Fig. 8.1.

A permanently maintained AWPM database linked to web pages can form the basis of a pest outbreak risk warning system for pest management. Proper use of regional or areawide pest databases with Internet technology has the potential to provide a valuable service to growers, with relatively little work required from persons involved in sampling and monitoring pest populations in agriculture, above and beyond their current workloads. While there is considerable effort required to create a database application for region-wide pests, once such a system is developed, tested and revised it can be extremely useful for real-time updating and visualizing of pest conditions over broad geographic areas.

When considered on an individual basis, where sampling may be limited to a few fields, the value of the data for assessing regional pest status is limited. But, when many individuals each make a small effort to collect data and combine it in a coordinated fashion, the database has the capability for triggering pest-scouting activities in a timely manner throughout a region. When sample points are automatically georeferenced using a hand-held computer with an attached ground GPS receiver

(a)

(b)

(c)

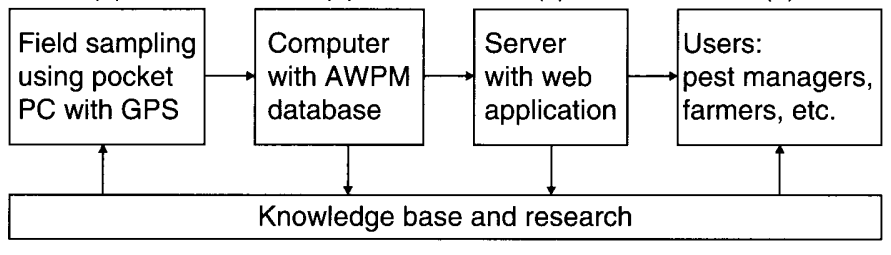

Information flows

Fig. 8.1. Flow of data from field to end-users: (a) data collection in the field using a palm-top computer equipped with a Global Position System unit; (b) data transformation from palm-top computer into an areawide pest management database; (c) connection between a database and an Internet application providing field data or descriptive statistics for end-users (pest managers, growers, scientists, administrators and other interested personnel); and (d) interpretation of data for pest management by end-users. 
while collecting data, spatio-temporal analysis and display of the data can be easily accomplished. Such an analysis of spatially referenced population data is an obvious and logical activity to aid in understanding the spatial distribution and dynamics of the pest populations in relation to concomitant biotic and abiotic environmental factors.

Today, there are specialized statistical software packages such as the STATISTICAL ANALYSIS SYSTEM $^{(}$(SAS Inc., Cary, North Carolina, USA) and SURFER ${ }^{\odot}$ (Golden Software Inc., Golden, Colorado, USA) that facilitate construction of surfaces displaying pest density in space. Each surface can be considered analogous to a solution of a diffusion equation if we assume that the distribution of the pest species in an area follows the laws of thermodynamics. This subject falls outside the scope of this chapter, but it is notable that numerous papers dealing with mathematically described arthropod spatio-temporal population dynamics through partial differential equations have recently been published (e.g. Yamamura, 2002; Bianchi, 2003; Filipe and Maule, 2003; Eason et al., 2004).

The information, accumulated in a well-constructed, comprehensive database, has potential utility long after the AWPM research programme ends. For example, data on the population dynamics of species collected over broad geographic areas and then compiled during a study can be a source of information for different space-time studies. It can be a database used to develop simulation models of pest population dynamics or to explore the utility of various pest management strategies. Once a database is constructed it requires little effort to maintain, and it has a much longer lifespan than the duration of a particular project.

\section{An Example of Database Development}

This section describes one way to develop an inexpensive database application for a spatially distributed AWPM project, but the reader should be aware that there are many other approaches and tools to accomplish the development of such a database (e.g. Isard et al., 2006). In our example, database development requires only a dedicated computer with moderate capabilities and a link to the Internet. The computer should have either Windows 2000 Advanced Server or Windows 2003 Server operating system installed. We developed the DBMS using Oracle 9i RDBMS ${ }^{\odot}$. The Oracle $9 \mathrm{i}$ RDBMS ${ }^{\odot}$, with the choice of an operating system, can be downloaded at http://www.oracle.com. Oracle 9i kit installation has two distinct parts: the server and the client components. The server component is used to generate and install an instance of the Oracle database on a separate computer. The client component has to be installed on all computers that will be connected to the future database. It contains two distinct components: the Oracle Net Manager (ONM) and the library of classes that generate Oracle objects for database connection. The installation process of server and client components is very well documented and there are numerous sites on the Internet providing information about Oracle 9i (Oracle 9i, 2003).

During the database creation process, the developer will be prompted by the Database Configuration Assistant to give a unique Global Database Name to the future database. This unique name, with the server IP address and its port number, 
will be used by the ONM to establish a remote connection database via the Internet from a distant computer using TCP/IP protocol. The ONM is a very powerful tool that provides enterprise-wide connectivity solutions in a distributed, heterogeneous computing environment. It reduces the complexity of network configuration and management, maximizes performance and improves network diagnostic capabilities. It also enables a network session from a client application to an Oracle database server. Once a network session is established, the ONM acts as a data courier for the client application and the database server. The ONM is responsible for establishing and maintaining the connection between the client application and database server, as well as exchanging messages between them. The ONM can perform these functions because it is located on every computer in the network (Oracle9i, 2002; see Fig. 8.2).

The ONM is an alternative to the Microsoft ODBC (Open Database Connectivity) technology. From our point of view, ODBC is more complicated and less stable. One more reason to use the Oracle 9i RDBMS is that inside of Oracle products exists another tool: Oracle Objects for OLE, called 'OO4O', which is a COM (Component Object Model) component that facilitates software development. The OO4O can easily be integrated in Microsoft Visual Studio $6.0^{\odot}$ and permits software development using Visual Basic or Visual $\mathrm{C}++$. The $\mathrm{OO} 4 \mathrm{O}$ can also be used from Microsoft Visual Basic for Application ${ }^{\odot}$ (VBA), which is a tool of each Microsoft Office component.

For example, from an Excel table using VBA and OO4O, the user can easily establish a remote connection with an AWPM database. The code presented in Appendix $\mathrm{A}$ is an example of such a VBA application. It is presented in the $\mathrm{OO} 4 \mathrm{O}$ documentation. The first 'Set' operator will start the 'Oracle In Process Server', which provides an interface between our application and the Oracle database. The second 'Set' operator will connect our Excel table to the 'Exampledb' database, where 'scott' is a user name and 'tiger' is his password. When an Oracle 9i database is generated, the 'Exampledb' database and the 'scott' user are created automatically.

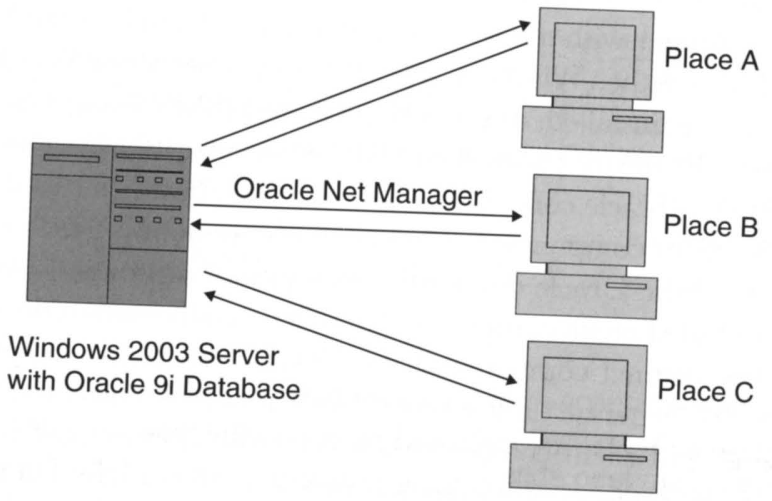

Fig. 8.2. A stable link between a Windows Server 2003 with an Oracle 9i database and a series of computers with different platforms at remote locations using Oracle Net Manager. 
The third 'Set' operator will create a set of records and will select all the rows from the 'emp' table and assign the result to the global EmpDynaset variable. The parameter in this operator is an expression written in Structured Query Language (SQL), and it specifies what information will be withdrawn from the database. The next operators will put the contents of the EmpDynaset variable on 'Datasheet' worksheet of our Excel table.

Once the structure of a common AWPM database is finished, the respective tables can be generated inside the database using SQL. Appendix B contains an example of such a table creation. This example can be executed directly on the server or remotely from an application. Table organization should diminish the volume of stored information. For example, the repeated information should be stored in separate tables and be linked to other tables by common keys.

Once the database development is finished, we can start to develop a software application to facilitate remote data input. The steps described here are widely applied today between programmers. However, because this field of knowledge progresses rapidly it is likely that this approach will soon evolve.

As a rule there are several programming languages inside Microsoft Visual Studio (MVS): Visual Basic, Visual C++ and Java. The most recent version of MVS (MVS .NET) has one more language: C\#. Another feature of this version is that all these languages have in their background the same hierarchy of classes; the applications developed in one language can be used in another. This work is done by the Microsoft .NET version 2.0 work frame.

The OO4O within MVS is used exactly in the same manner as in the example for VBA from Appendix A. It is a good idea to develop a common application for all participants in an AWPM project. It can be easily performed, for example, in Visual Basic. Once the application is developed it can be uploaded to an ftp site with necessary install instructions for all users. Such an application should be able to read Excel tables that will contain sampling data from all places involved in the AWPM project. It also should have the capability to check the format of all data before they are added to the database. For security reasons it is a good idea to protect the connection to the AWPM database by a user name and password. For this, it is enough to organize a separate user table inside the AWPM database. The creation of such a table is presented in Appendix B.

Once the AWPM database has enough information, and we need to share it with other people, it is a good idea to develop a web application that will let users visualize and download data. Such a web application can be developed within MVS. The latest version of MVS .NET has several facilities for this purpose. In particular, it allows development of a web application using the Active Server Pages (ASP) technology. ASP is Microsoft's product that enables Internet pages to be dynamically created using HTML, scripts and reusable ActiveX server components. ASP is a component of the Internet Information Server (IIS) that runs on Windows NT platforms. When a browser requests an ASP page from a server, the server generates the web page with HTML code and gives it to the browser. ASP.NET is the next version of ASP. ASP.NET allows programmers to use a fully featured programming language such as C\# or VB.NET to build web applications rapidly. The ASP.NET is mostly used to access data from a database, and those data are then built into the returned web page 'on the fly'. 
Our AWPM project web site will be used as an example of ASP technology: it is located at http://199.133.145.58/GPIPMWebApplication/WebAWPMPForm.aspx and is linked to an Oracle 9i database on a Windows 2003 Server. The structure of our database corresponds to the field-collected data and it is schematically represented in Fig. 8.3. Each rectangle stands for a separate table that corresponds to a distinct type of sampling; a common key links the tables. The AWPM project for wheat was conducted in the Great Plains of the USA from 2002 to 2006. This region was chosen because cereal crops, primarily rain-fed winter wheat, dominate it. Growers across the region use a range of agronomic practices for wheat production. In the south, growers commonly use winter wheat fields as pasture for cattle from November to February, whereas in the north wheat is used solely for grain production. Wheat efficiently uses the soil moisture accumulated during the winter, which is important in the Western Great Plains where annual precipitation is $<400 \mathrm{~mm}$.

The major pests of wheat and other cereals, including barley and sorghum, in the Great Plains are several aphid species. Two of these aphids, the greenbug $(\mathrm{GB})$, Schizaphis graminum (Rondani) and the Russian wheat aphid (RWA), Diuraphis noxia (Mordvilko), are common economically important pests. The RWA was introduced into the USA in 1986 from Mexico (Halbert and Stoetzel, 1998). Depending upon local climatic conditions, only one of these species is important, while both are important in others. The economic importance of these aphids was discussed in Morrison and Peairs (1998).

There are several objectives of the AWPM project, the most important of which are to: (i) estimate two distinct agricultural methods - with crop rotation and without it (non-traditional and traditional farming); (ii) improve the monitoring of aphid mega-populations on a large scale; (iii) determine the role of the parasites and predators as regulators of the aphid density; and (iv) investigate environmental conditions that cause aphid outbreaks. All these, together, should improve the potential for effective IPM through the development of forecast models and other predictive tools.

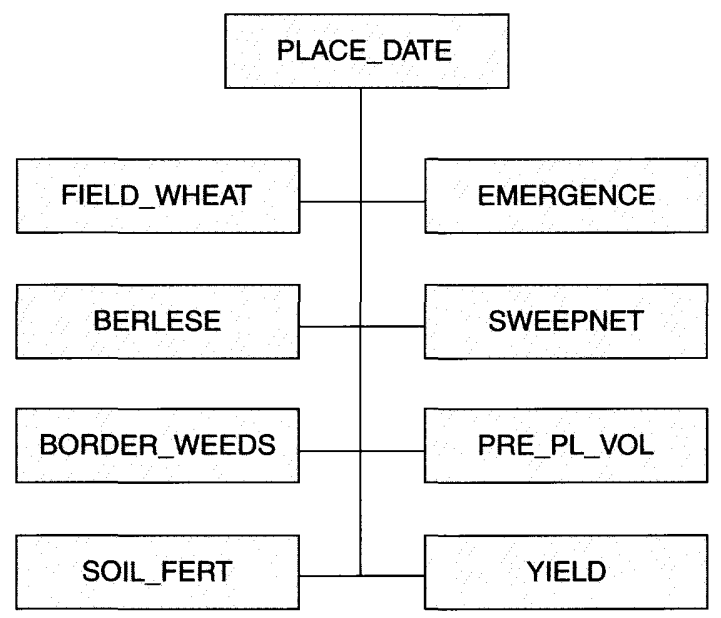

Fig. 8.3. The structure of Oracle $9 i$ database; each rectangle represents a table, and tables are linked by a common key. 
Our AWPM project involves universities in Colorado, Kansas, Nebraska, Oklahoma and Texas; these states represent the western and southern Great Plains. Up to six rainfed farms were selected in each state and a series of observations were made bi-weekly or monthly on wheat fields on each farm, depending on the insect abundance. There are 23 study farms, and the location of each farm is represented on our web site map by a shaded rectangle (see Fig. 8.4). The user can choose a farm by clicking on the corresponding rectangle and, on the next web page, will be prompted to choose one of several sampling methods.

Most of the fields sampled were rectangular, and size varied from approximately 100 to 130 ha. Each field was split up into 25 equal-sized grid cells, and one sample was established at the centre of each cell. Coordinates of each sample were taken with a GPS receiver to determine its location. The borders of each field were digitized using GIS software (FarmWorks Inc., Hamilton, Indiana, USA) installed on a pocket personal computer (PC). The pocket PC is equipped with a GPS unit, and the location of each sampling point was determined with high precision.

There were four different insect samples taken in the fields: two were made at each point and the remaining two were brought to the laboratory. We developed a simple template on a pocket PC to facilitate entry of each sample in the field. The first field sample was a visual count, and it consisted of examining four tillers in a

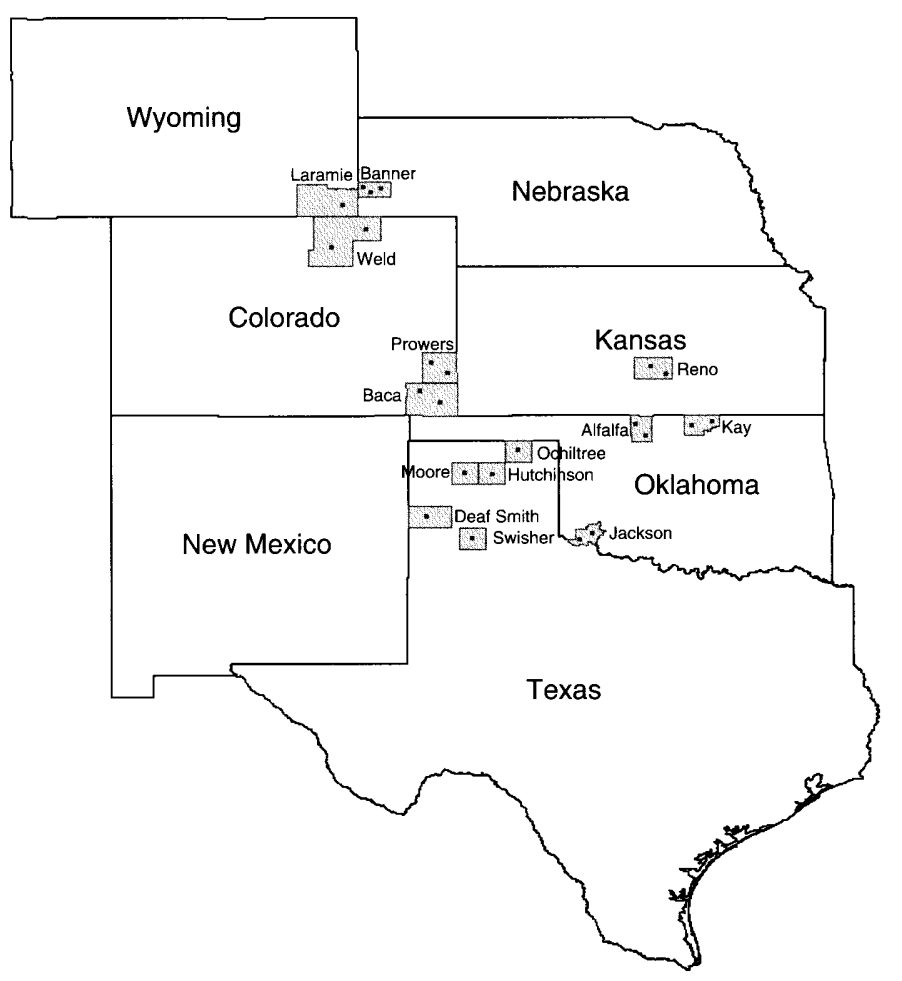

Fig. 8.4. Location of the sampling fields in the south-central part of the Great Plains, USA. 
radius of $1 \mathrm{~m}$ around the main sampling point. Three groups of objects (insects) (aphids, aphid mummies and predators) were counted. The counts were directly entered in a template with 58 columns on the palm computer. The columns of this table were common for all sampling fields, and the table structure corresponded to the common protocol established by agreement among all research teams involved in the AWPM project. There were three distinct aphid species sampled: the greenbug, Russian wheat aphid and bird cherry oat aphid, and if there were other species they were entered in the column 'Other Aphids'. As a rule, this group consisted of the rice root aphid (Rhopalosiphum rufiabdominalis), the corn leaf aphid (R. maidis) and the English grain aphid (Sitobion avenae). Black and gold mummies were counted separately to distinguish two distinct groups of parasitoids.

The other visual sample made in the field is an aphid predator count in two-row-foot of wheat at each sample location. In this predator group, important species were individually distinguished, e.g. Hippodamia convergens, Coccinella septempunctata, Coleomegilla maculata and $H$. sinuata, but some predators that corresponded to the same genus (family, tribe, etc.) were combined as a single entry to reduce the volume of collected information. Other predators recorded included spiders, nabids, carabids, staphylinids, syrphids, Geocoris, Orius, Scymnus and green and brown lacewings. We also sampled other important pests of wheat such as pest mites, fall armyworm, armyworm, army cutworm and the 15 most important weeds.

There were three more sampling methods used to determine more accurately and precisely the density of categories of insects at each sampling point. Sweep net sampling was performed to estimate populations of highly mobile predators, such as lady beetles, that are difficult to count accurately by the visual count method. Berlese sampling was done to determine more precisely aphid density. Emergence canister sampling was performed to obtain more accurate estimation of parasitism. Data from each of these three sampling methods have their individual table within the database. Along with these samples, weather data (precipitation and temperature) were collected throughout the growing season at $15 \mathrm{~min}$ intervals for all fields using Watchdog Data loggers, model 425iR (Spectrum Technology Inc., East-Plainfield, Illinois, USA).

Using C\# from Microsoft Visual Studio.NET, we developed an Internet application and then made a link between our AWPM database and our web site (see above) that facilitated visualization of the data. When a visitor logs on to the web site, they can choose a field on the map and will then be prompted to select a date for one of the eight sample types: field (visualization), Berlese, emergence canister, sweepnet, border weeds, pre-plant volunteer wheat, soil fertility and yield. After choosing the sampling date from a combo box, the visitor can simply click on the corresponding button and the data set selected will be visible on their browser in the form of a table. The data can be also downloaded in the form of an Excel table by clicking the corresponding button.

If the visitor chooses a data set collected in one of the fields that contain three categories of data: aphids, parasitoids and predators, they will also have the capability to examine three-dimensional surfaces for each category. If the selected data are not all equal to zero, each surface will describe the spatial distribution of abundance of the selected aphid, parasitoid or predator for the chosen date. The surfaces are automatically generated on our web server by 'SURFER 8' software using kriging 
(Surfer, 2006). If there is enough information to calculate a linear variogram, kriging will generate a surface that has a smooth form. All three figures show spatial allocations of the insect populations in the selected field for the chosen date.

The web application described above is a prototype for a larger web infrastructure with online analytical processing. Figures 8.5 and 8.6 represent the total aphid densities, including GB and BCOA, collected on 24 March 2003 and on 2 April 2003 in wheat field No. 1 located in Jackson County, Oklahoma. The aphid density on the first date was much higher than on the second date. It can be easily analysed by accessing our online database and selecting the field from 23 fields. It can be seen on the first date that parasitoid density was very low and total predator density was zero. The total parasitoid and predator densities are represented in the Figs 8.7 and 8.8, respectively, for 2 April 2003. It can be seen that they were high, but at the same

\section{OK_JACKSON_1_Field_3_24_2003 Total of Aphids}

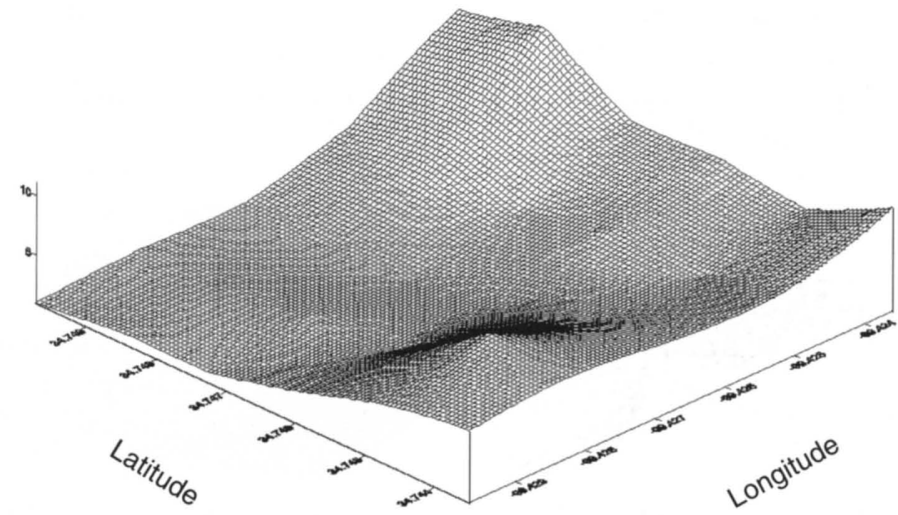

Fig. 8.5. The total aphid density in field No.1 located in Jackson County, Oklahoma, on 24 March 2003.

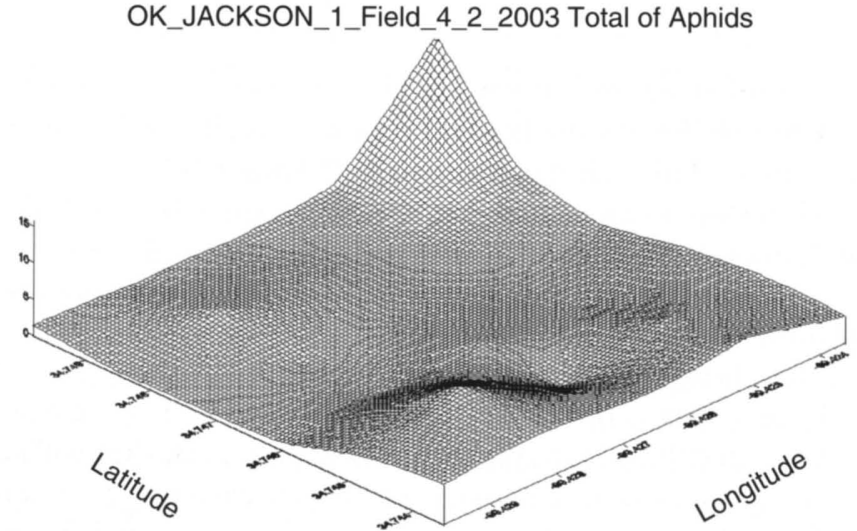

Fig. 8.6. The total aphid density in field No.1 located in Jackson County, Oklahoma, on 2 April 2003. 


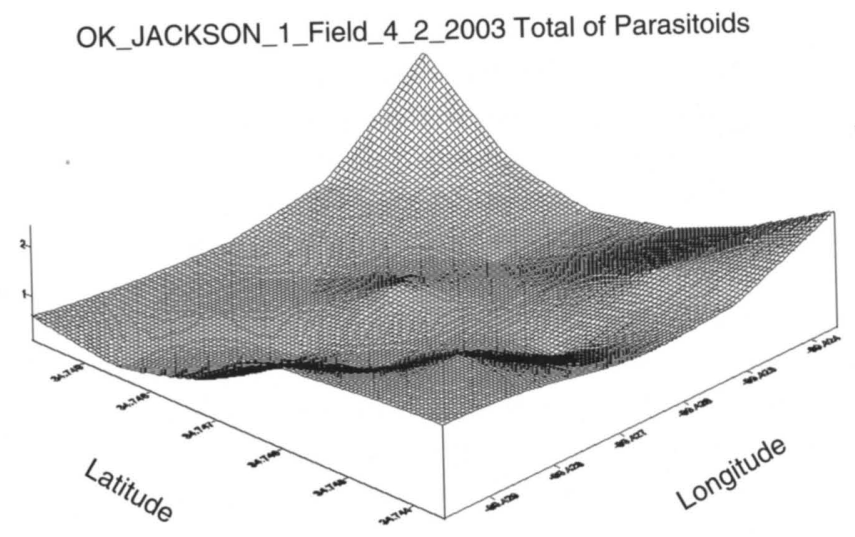

Fig. 8.7. The total parasitoid density in field No.1 located in Jackson County, Oklahoma, on 2 April 2003.

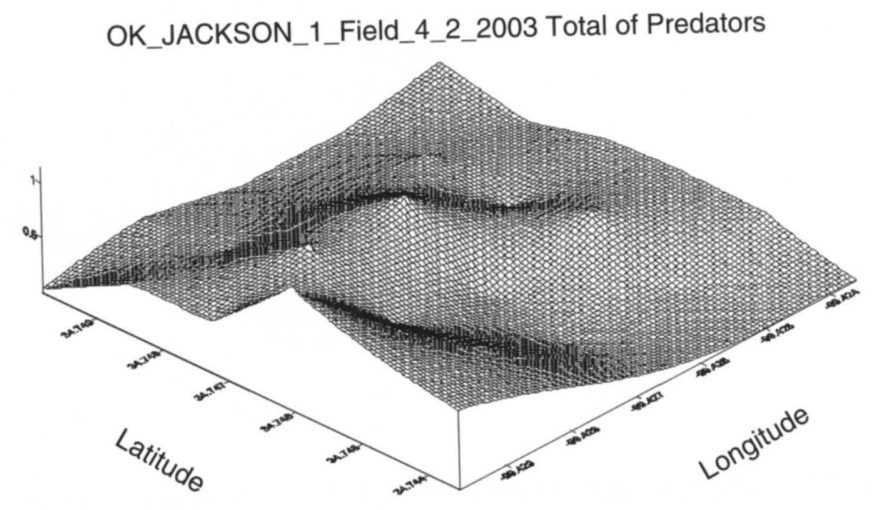

Fig. 8.8. The total predator density in field No.1 located in Jackson County, Oklahoma, on 2 April 2003.

time the aphid density was low (see Fig. 8.6). This suggests that the high aphid density on 24 March 2003 was followed by an increase in predators and parasitoids, which had controlled the aphid population by 2 April 2003.

The example above shows some new possibilities of our approach in interpreting insect population evolution in time and space. Presently, there are numerous theoretical publications explaining spatial and temporal population dynamics by diffusion equations. These theoretical conclusions are not validated by real data because it is difficult to bring them together. The AWPM database can do it. First, it is possible to determine whether the insect population's behaviour is similar to a physical system that follows the thermodynamic law like heat in a solid body. Using the AWPM database this can be done at smaller (field) or larger (landscape or region) scale. However, this is not the only possibility of the AWPM database in analysing insect population dynamics. We can also estimate the climatic influence on this process, or the influence of different farming methods on pest abundance, etc. 


\section{Conclusions}

Today, the DBMS can easily be implemented in pest management programmes such as AWPM projects. A database application achieves full functionality and IT elements only if it is properly organized. For this purpose, careful preliminary coordination should occur between all teams involved in the project, so that database structure satisfies anticipated needs for data collection, storage, manipulation and analysis. At the outset of a project, efforts should be focused on unifying the data-gathering methods and protocols, and the structure of the information to be collected during the project. The next step is to analyse and develop the structure of the future database. This work should include the requirements and the right IT tools to develop a database. Presently, there are numerous commercially available tools for the purpose of database development, but they differ markedly in their performance and price, and the right choice can be a key to successful database development.

The database concept can contribute to future progress in IPM, because it forms an information source for IPM programme development and implementation. One exciting and interesting research avenue is the development of forecasting methods to predict pest population dynamics in space and time. The database might contain, for example, the data to assess the relationship between environmental conditions and the occurrence of pest outbreaks. Furthermore, it can provide the data to evaluate the roles of predators and parasitoids as pest population regulators. This is an important point, because implementation of a spatially distributed database provides the ability to study the dynamics of insect populations and their interactions using a spatio-temporal approach in a way not possible within the framework of a typical research project.

\section{References}

Bianchi, F.J.J.A. (2003) Usefulness of spatially explicit population models in conservation biological control: an example. Landscape management for functional biodiversity. $I O B C$ wprs Bulletin 26, 13-18.

Date, G.J. (2003) An Introduction to Database Systems. 8th edn., Addison Wesley, New York.

Dent, D. (1995) Integrated Pest Management. Chapman \& Hall, London.

Eason, A., Tim, U.S. and Wang, X. (2004) Integrated modeling environment for statewide assessment of groundwater vulnerability from pesticide use in agriculture. Pest Management Science 60, 739-745.

Elliott, N.G., Hein, G.L., Carter, M.R., Burd, J.D., Holtzer, T.O., Armstrong, J.S. and Waits, D.A. (1998) Russian wheat aphid (Homoptera: Aphididae) ecology and modeling in Great Plains agricultural landscapes. In: Quisenberry, S.S. and Peairs, F.B. (eds) Response Model for an Introduced Pest - the Russian Wheat Aphid. Entomological Society of America, Lanham, Maryland, pp. 31-65.

Elliott, N.C., Royer, T.A., Giles, K.L., Kindler, S.D., Porter, D.R., Elliott, D.T. and Waits, D.A. (2004) A web-based decision support system for managing greenbugs in wheat. Crop Management doi: 10.1094/CM-2004-09XX-01-MG.

EXAMINE (2000) http://www.rothamsted.bbsrc.ac.uk/examine/ 
Faust, R.M. and Chandler, L.D. (1998) Future programs in areawide pest management. Foumal of Agricultural Entomology 15, 371-376.

Filipe, J.A.N. and Maule, M.M. (2003) Analytical methods for predicting the behavior of population models with general spatial interactions. Mathematical Biosciences 183, $15-35$.

Folkedal, A. and Breving, C. (2004) VIPS - a web-based decision support system for crop protection in Norway. In: Thysen, I. and Hocevar, A. (eds) Online Agrometeorological Applications with Decision Support on the Farm Level. COST Action 718: Meteorological Applications for Agriculture. DINA Research Report No. 109, pp. 18-27.

Halbert, S.E. and Stoetzel, M.B. (1998) Historical overview of the Russian wheat aphid (Homoptera: Aphididae). In: Quisenberry, S.S. and Peairs, F.B. (eds) Response Model for an Introduced Pest - the Russian Wheat Aphid. Entomological Society of America, Lanham, Maryland, pp. 12-30.

Human Genome Project (2003) http://www.ornl.gov/sci/techresources/Human_Genome/ home.shtml

Isard, S.A., Russo, J.M. and DeWolf, E.D. (2006) The establishment of a national pest information platform for extension and education. Plant Health Progress, doi 10.1094/ PHP2006- 0915- 01-RV.

King, G.J. (2004) Bioinformatics: harvesting information for plant and crop science. Seminars in Cell and Developmental Biology 15, 721-731.

Knight, J.D., Tatchell, G.M., Norton, G.A. and Harrington, R. (1992) FLYPAST: an information management system for the Rothamsted aphid database to aid pest control research and advice. Crop Protection 11, 419-426.

Kogan, M. (1998) Integrated pest management: historical perspectives and contemporary development. Annual Review of Entomology 43, 243-270.

Legg, D.E. and Bennett, L.E. (1992) A mobile workstation for use in integrated pest management program on the Russian wheat aphid. In: Morrison, W.P. (ed.) Proceedings of the 5th Russian Wheat Aphid Conference, 26-28 January 1992, Fort Worth, Texas, pp. 66-69.

Legg, D.E. and Bennett, L.E. (1993) Development of a transportable computing system for on-site management of the Russian wheat aphid in wheat. Trends in Agricultural Science and Entomology 1, 31-39.

Mann, B.P., Wratten, S.D. and Watt, A.D. (1986) A computer-based advisory system for cereal aphid control. Computers and Electronics in Agriculture 1, 263-270.

Morrison, W.P. and Peairs F.B. (1998) Response model concept and economic impact. In: Quinsenberry, S.S. and Peiars, F.B. (eds) Response Model for an Introduced Pest - the Russian Wheat Aphid. Entomological Society of America, Lanham, Maryland, pp. 1-11.

Murali, N.S., Secher, B.J.M., Rydahl, P. and Andreasen, F.M. (1999) Application of information technology in plant protection in Denmark: from vision to reality. Computers and Electronics in Agriculture 22, 109-115.

Nemenyi, M., Mesterhazi, P.A., Pecze, Z. and Stepan, Z. (2003) The role of GIS and GPS in precision farming. Computers and Electronics in Agriculture 40, 45-55.

Neufeld, M.L. and Cornog, M. (1986) Database history: from dinosaurs to compact discs. Fournal of the American Society for Information Science 37, 183-190.

Ohio Geospatial Program (2003) http://geospatial.osu.edu/resources/hand-heldgps.html

Oracle9i (2002) Net Services Administrator's Guide (http://www.oracle.com/pls/db92/db92. docindex).

Oracle9i (2003) Database Release Notes (http://download-east.oracle.com/docs/html/B10924_ $01 /$ toc.htm).

Perini, A. and Susi, A. (2004) Developing a decision support system for integrated production in agriculture. Environmental Modeling and Software 19, 821-829.

SAS Institute (1990) SAS/STAT User's Guide, Version 6. SAS Institute, Cary, North Garolina. 
Sivertsen, T.H. (2005) Implementation of a general documentation system for web-based administration and use of historical series of meteorological and biological data. Physics and Chemistry of the Earth 30, 217-222.

Surfer (2006) http://www.goldensoftware.com/products/surfer/surfer.shtml

Random House Webster's Unabridged Electronic Dictionary, 2nd edn., Copyright ${ }^{\circledR} 1996$.

Tatchell, G.M. (1991) Monitoring and forecasting aphid problems. In: Peters, D.C., Webster, J.A. and Chlouber, C.S. (eds) Aphid-Plant Interactions: Populations to Molecules. Oklahoma Agricultural Experiment Station, MP-132, Norman, Oklahoma, pp. 215-231.

Taylor, L.R. (1977) Migration and the spatial dynamics of an aphid, Myzus persicae. Fournal of Animal Ecology 46, 41 1-423.

Xia, Y., Stinner, R.E. and Chu, P.-C. (2002) Database integration with the web for biologists to share data and information. Electronic Journal of Biotechnology 5, 154-161.

Yamamura, K. (2002) Dispersal distance of heterogeneous populations. Population Ecology 44, 93-101.

Zadoks, J.C. (1981) EPI-PRE: a disease and pest management system for winter wheat developed in the Netherlands. EPPO Bulletin 11, 365-369.

Zintzaras, E. and Tsitsipis, J.A. (2003) Gentaur database: an information system for aphid surveys and pest control. Fournal of Applied Entomology 127, 534-539.

\section{Appendix A}

An example of VBA application that demonstrates how Oracle Objects for OLE can be used to access Oracle 9i database.

Sub Get_Data()

'Create and initialize the necessary objects

Dim OraSession As Object

Dim OraDatabase As Object

Dim EmpDynaset As Object

Dim ColNames As Object

Set OraSession = GreateObject('OracleInProcServer.XOraSession')

Set OraDatabase = OraSession.OpenDatabase('Exampledb', 'scott/tiger', 0\&)

Set EmpDynaset = OraDatabase.DbCreateDynaset('select * from emp', 0\&)

'Using field array, ie. ColNames('ename').value, is significantly faster than using 'field lookup, ie. EmpDynaset.fields('ename').value

Set ColNames $=$ EmpDynaset.Fields

'Place column headings on sheet

For icols $=1$ To ColNames. Count

Worksheets $\left({ }^{\text {'DataSheet' }}\right) \cdot$ Cells $(1$, icols $) \cdot$ Value $=$ ColNames(icols -1$) \cdot$ Name

Next

'Place data on sheet using CopyToClipboard

EmpDynaset.CopyToClipboard -1

Sheets('DataSheet').Select

Range('A2').Select

ActiveSheet.Paste

End Sub. 


\section{Appendix B}

Creation of 'Users' table inside of 'Exampledb' database using SQL language.

CREATE TABLE 'EXAMPLEDB'.'USERS'

('USER_NAME' VARCHAR2(25),

'PASSWORD' VARGHAR2(25),

PRIMARY KEY ('USER_NAME') ENABLE); 